\title{
Retraction Note to: A Survey on Recent Vision-Based Gesture Recognition
}

\author{
Haitham Badi ${ }^{1,2}$
}

Published online: 16 March 2017

(C) Springer Science+Business Media Singapore 2017

\section{Retraction Note to: Intell Ind Syst (2016) 2:179-191 DOI 10.1007/s40903-016-0046-9}

The publisher retracts the above-mentioned article per the Committee on Publication Ethics (COPE) guidelines on selfplagiarism. The article has significant overlap with two other publications by the same author:

- Haitham Badi, Mohammed Fadhel, Sana Sabry, Mohamed Jasem A Survey on Human-Computer Interaction Technologies and Techniques, International Journal of Data Science and Analytics (2016) 2:1 doi:10.1007/ s41060-016-0018-x
- Haitham Hasan, Sameem Abdul-Kareem HumanComputer Interaction Using Vision-Based Hand Gesture Recognition Systems: A Survey, Neural Computing and Applications (2014) 25:251 doi:10.1007/ s00521-013-1481-0

The online version of the original article can be found under doi: 10 . 1007/s40903-016-0046-9.

\section{Haitham Badi}

haitham@siswa.um.edu.my

1 College of Business Informatics, University of Information

Technology and Communications, Baghdad, Iraq

2 University of Malaya, 50603 Kuala Lumpur, Malaysia 